\title{
A LASER INDUCED FLUORESCENCE STUDY OF VIBRATIONAL ENERGY TRANSFER IN DIDEUTEROMETHANE
}

\author{
V.A. APKARIAN and Eric WEITZ \\ Department of Chemistry, Northwestern Uriversity, \\ Evanston, Ilinois 60201, USA
}

Received 30 July 1978

$\mathrm{V}-\mathrm{V}$ and $\mathrm{V}-\mathrm{T} / \mathrm{R}$ rates of $\nu_{1}, \nu_{2}, \nu_{3}, \nu_{6}, \nu_{8}$, and $\nu_{9}$ of $\mathrm{CH}_{2} \mathrm{D}_{2}$ were measured and are reported. The deactivation efficiencies of rare gas coilision partners were measured and calculated by SSH theory, the results are reported ard discussed. Possible V-V patinways are presented and discussed.

\section{Introduction}

In recent years, a wealth of information has been uncovered about vibration to vibration $(V-V)$ and vibration to translation/rotation ( $V-T / R)$ energy transfer processes in polyatomic molecules, much of it by the technique of laser induced fluorescence $[1,2]$.

The substituted methanes have been the subject of exiensive research in this area. With respect to energy transfer pathways, some of the betfer understood molecules are: the symmetric top, monosubstituted methyl halides [2] and the spherical top, methane $[3,4]$. In the symmetric top methyl halides, all vibrational transitions are allowed by dipole selection rules. In $\mathrm{CH}_{2} \mathrm{D}_{2}$ the $\mathrm{C}_{2 \mathrm{v}}$ symmetry results in some dipole non-allowed transitions e.g., the small energy gap. $\nu_{7} \rightarrow \nu_{9}$ transition*. Hence it was felt that an understanding of the vibrational energy transfer processes in $\mathrm{CH}_{2} \mathrm{D}_{2}$ could make a valuable contribution to existing knowledge and yield information with respect to the potential role of symmetry on the rates of $V-V$ processes.

A preliminary report of this work has been previously presented [5].

* $\mathrm{CH}_{4}$ has dipole non-allowed transitions namely $\mathrm{A}_{1} \rightarrow \mathrm{A}_{1}$ and $A_{1} \rightarrow E$. Therefore any diople non-allowed $V-V$ step would involve $v_{1}$, e.g. $\nu_{1} \rightarrow v_{2}$, but since $\nu_{1}$ to ground is also infrared non-allowed, its behavior has not been directly investigated.

\section{Experimental}

The basic experiment consists of monitoring the time dependence of fluorescence originating from all of the infrared active fundamentals of $\mathrm{CH}_{2} \mathrm{D}_{2}$ except for the initially pumped fundamental, the $\nu_{7}$ mode (see fig. 1). The details of the experimental method and apparatus have been reported previously [6], therefore only a brief description is ireluded here.

Strong fluorescence from $\mathrm{CH}_{2} \mathrm{D}_{2}$ can be observed following irradiation of the gas with the output of a $\mathrm{CO}_{2}$ laser operating on the $\mathrm{R}(22)$ line of the $9.6 \mu$ band. Weakez fluorescence is observed when the laser is operated on a variety of other lines, including the $R(40), R(8), P(20), P(30)$ and $P(34)$ lines of the $9.6 \mu$ band. The laser is $Q$-switched at $100 \mathrm{~Hz}$ and produces a pulse of approximately $3 \mathrm{~mJ}$, as measured by a calibrated thermopile. The detectors used vary as a function of the fluorescence wavelength to be observed. For 3-5 $\mu$ fluorescence, $\nu_{1}, \nu_{6}, \nu_{2}$ and $\nu_{8}$, an In : Sb detector was used. The response of the detector and entire electronic chain was $0.9 \mu \mathrm{s}$ [6] . For 6.8 i fluorescence, $\nu_{3}$, a $\mathrm{Au}$ : Ge detector was used, most measurements were done with a $5 \mathrm{k} \Omega$ load resistor, which produced a $1.2 \mu$ s response time for the detector and following electronic chain. For fluorescence in the $8-10 \mu$ region, $\nu_{9}$ and $\nu_{4}$, a $\mathrm{Cu}: \mathrm{Ge}$, liquid $\mathrm{He}$ cooled detector was used with a $5 \mathrm{k} \Omega$ resistive load yielding a response time of approximately $1 \mu \mathrm{s}$. 


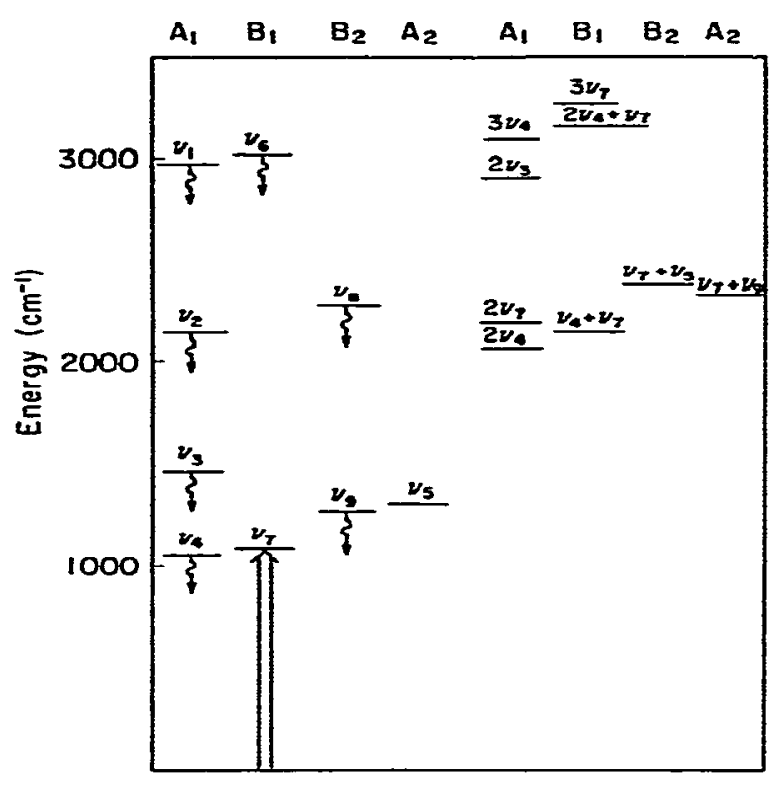

Partial Energy Level Diagram of $\mathrm{CH}_{2} \mathrm{D}_{2}$

Fig. 1. Vibrational energy levels of $\mathrm{CH}_{2} \mathrm{D}_{2}$ are arranged according to their symmetries. The first four columns show the fundamentals; sone overtones and combination bands are shown in the second four columns. The solid arrow indicates the laser pumped state and the wavy arrows indicate the observed states.

$\mathrm{CH}_{2} \mathrm{D}_{2}$ of 98 at. \% minimum nominal purity was obtained from Merck and Co. A mass spectrometric analysis showed a $\mathrm{CH}_{2} \mathrm{D}_{2}$ content of $>99 \%$ with the major impurities being other deuterated methanes. The gas was thus used without further purification.

\section{Results}

All experiments reported on in this paper were done using the $R(22), 9.6 \mu \mathrm{CO}_{2}$ laser line at $1080 \mathrm{~cm}^{-1}$ which overlaps the $\nu_{7}$ band of $\mathrm{CH}_{2} \mathrm{D}_{2}$. Fluorescence was observed from the levels shown in fig. 1. Interference filters were used to isolate fluorescence from a single level (or set of closely coupled levels) and to verify that the levels were in the appropriate wavelength region.

Fluorescence from $v_{1}$ and $v_{6}$ was not separated, due to their proximity and extensive rotational overlap. For the same reason they are assumed to be fully equilibrated on the timescale of $V-V$ processes in the molecule and therefore will be treated as a single state, $\left[v_{1} ; v_{6}\right]$.

$\nu_{2}$ and $\nu_{8}$ fluorescence was monitored through three different filters or filter combinations: $4.7 \mu$ band pass, $4.8 \mu$ long pass and sapphire, and $4.5 \mu$ long pass and sapphire. The $4.7 \mu$ b.p. and $4.8 \mu 1$.p. filters are expected to isolate primarily the $\nu_{2}$ state from $\nu_{8}$ while the $4.5 \mu 1$.p. and sapphire would be expected to transmit emission from both states. All $V-T$ and $V-V$ measurements with these filter sets were identical and for the purposes of this paper the states are considered to behave identically. However, efforts are being made to completely isolate each state using narrow band pass filters [7] -

The $\nu_{3}$ state is easily isolated in the $6.8 \mu$ region and the $\nu_{9}$ state was also isolated as was the $P$ branch of the $\nu_{4}$ state. However laser scatter precluded accurate measurements being performed on the $\nu_{4}$ state and greatly complicated attempts at the measurement of $\nu_{9}$ risetimes at low pressures.

The $\nu_{5}$ transition at $1300 \mathrm{~cm}^{-1}$ was not observed. It is an infrared non-allowed transition by strict dipole selection rules though it has been observed as a weak band in the absorption spectrum and its presence is attributed to Coriolis coupling [8].

The $V-T / R$ relaxation rates of all reported states were measured at pressures ranging between 0.1 and 25 torr. All relaxation signals were single exponencial and a plot of relaxation rate versus pressure was linear from approximately 0.5 to 25 ton. Below 0.5 torr, diffusion to the cell walls and subsequent deactivation of the molecules became important [9] .

All measured $V-T / R$ rates were the same within experimental error (see table 1) indicating that, as expected, the vibrational manifold is fully equilibrated on the $V-T / R$ timescale. $V-T / R$ rates were also measured in rare gas mixtures by monitoring fluorescence from $\nu_{3}$ and $\nu_{9}$. The measured rates from the two different states were the same within experimental error. A linear dependence of $1 / \tau$ versus rare gas pressure was observed in ali cases, with excellent correlation of the intercepts with the deactivation rate of the $\mathrm{CH}_{2} \mathrm{D}_{2}$ component of the mixture. Rare gas deactivation rates of $\mathrm{CH}_{2} \mathrm{D}_{2}$ and other relevant rare gas parameters are reported in table 2. Relative deactivation rates of $\mathrm{CH}_{2} \mathrm{D}_{2}$-rare gas collisions were calculated via Stretton's modification of SSH theory $[10,11]$. These are presented in table 2. Normalized probabilities are plotted in fig. 2. 
Table 1

Experimentally determined $V-V$ and $V-T / R$ rates in $C H_{2} D_{2}$

\begin{tabular}{|c|c|c|c|c|}
\hline State $^{a)}$ & Symmetry & Energy $\left(\mathrm{cm}^{-1}\right)$ & $\begin{array}{l}\mathrm{V}-\mathrm{V} \text { rate } \\
\left(\mathrm{ms}^{-1} \text { torm }^{-1}\right)\end{array}$ & $\begin{array}{l}V-T / R \text { rate } \\
\left(\mathrm{ms}^{-1} \text { torr }^{-1}\right)\end{array}$ \\
\hline$v_{4}$ & $A_{1}$ & 1033 & c) & c) \\
\hline$v_{7}$ & $\mathbf{B}_{3}$ & 1090 & \multicolumn{2}{|c|}{ pumped state } \\
\hline 29 & $\overrightarrow{\mathbf{B}_{2}}$ & 1234 & $263 \pm 12$ & $0.96 \pm 0.5$ \\
\hline$v_{5}$ & $A_{2}$ & 1300 & \multicolumn{2}{|c|}{ IR inactive mode } \\
\hline$v_{3}$ & $A_{1}$ & 1450 & $212 \pm 21$ & $1.03 \pm 0.05$ \\
\hline $\begin{array}{l}v_{2} \\
v_{8}\end{array}$ & $\begin{array}{l}A_{1} \\
B_{2}\end{array}$ & $\left.\begin{array}{l}2139 b) \\
2234\end{array}\right\}$ & $291 \pm 29$ & $1.02 \pm 0.05$ \\
\hline$v_{1}$ & $\mathbf{A}_{1}$ & 2976 & & \\
\hline$v_{6}$ & $\mathbf{B}_{1}$ & 3013 & $130 \pm 13$ & $1.03 \pm 0.05$ \\
\hline
\end{tabular}

a) State assignment as of Wimshurst and Bernstein [21].

b) $2139 \mathrm{~cm}^{-1}$ accepted instead of 2202 of ref. [21] according to the recommendation of Hiller and Straley [22] .

c) Observed but not measured due to interference from laser scatier.

Table 2

Deactivation of $\mathrm{CH}_{2} \mathrm{D}_{2}$ by rare gas collision partners

\begin{tabular}{|c|c|c|c|c|c|c|c|}
\hline \multirow{2}{*}{$\begin{array}{l}\text { Collision } \\
\text { partiner }\end{array}$} & \multirow{2}{*}{$\begin{array}{l}\left(x^{a}\right) \\
\text { (au) }\end{array}$} & \multirow{2}{*}{$\begin{array}{l}\left.\epsilon / K^{d} \mathbf{d}\right) \\
(\mathrm{K})\end{array}$} & \multirow{2}{*}{$\begin{array}{l}\left.a^{d}\right) \\
\text { (A) }\end{array}$} & \multicolumn{3}{|l|}{ Experimental } & \multirow{2}{*}{$\begin{array}{l}\text { Theoretical } \\
P_{1-0^{g}} \\
\text { (collision) }^{-1}\end{array}$} \\
\hline & & & & $\left(\mathrm{ms}^{-1}\right.$ torr $\left.^{-1}\right)$ & $\begin{array}{l}\left.Z_{1-0} \mathrm{e}\right) \\
\text { (collisions) }\end{array}$ & $\begin{array}{l}\left.P_{1-0}\right) \\
\text { (collision) }^{-1}\end{array}$ & \\
\hline $\mathrm{He}$ & 3.27 & 10.22 & 2.56 & 0.935 & 15000 & 1 & 1 \\
\hline $\mathrm{Ne}$ & 9.52 & 35.7 & 2.789 & 0.147 & 61000 & $2.5 \times 10^{-1}$ & $6.05 \times 10^{-3}$ \\
\hline Ar & 12.37 & 124 & 3.418 & 0.102 & 92000 & $1.7 \times 10^{-1}$ & $1.41 \times 10^{-3}$ \\
\hline $\mathbf{K r}$ & 14.8 & 190 & 3.61 & 0.067 & 135090 & $1.1 \times 10^{-1}$ & $5.44 \times 10^{-4}$ \\
\hline $\mathrm{Xe}$ & 15.8 & 329 & 4.055 & 0.053 & 185000 & $8.2 \times 10^{-2}$ & $2.01 \times 10^{-4}$ \\
\hline $\mathrm{CH}_{2} \mathrm{D}_{2}$ & 9.01 & $225 \mathrm{c})$ & 3.82 & 1.01 & 13300 & 1.15 & $4.76 \times 10^{-3}$ \\
\hline
\end{tabular}

a) Reduced mass of collision pair, $\mathrm{CH}_{2} \mathrm{D}_{2}$-rare gas.

b) Lennard-Jones parameter from ref. [23].

c) Obtained from ref. [24].

d) Hard sphere diameters obtained from ref. [23], for $\mathrm{CH}_{2} \mathrm{D}_{2}$ that of $\mathrm{CH}_{4}$ is used.

e) Number of collisions required for deactivation: $Z_{10}=2530\left[\left(\sigma_{a}+\sigma_{b}\right) / 2\right]^{2}(\mu)^{-1 / 2} \tau$, for $\sigma$ in $A, \mu$ in au, and $\tau$ in $\mathrm{ms}$ torr.

f) Probabinty of deactivation per collision relative to $\mathrm{He}: P_{1-0}=\left(Z_{1-0}\right) \mathrm{He} /\left(Z_{1-0}\right) \mathrm{X}$.

g) Relative probability of deactivation per collision calculated by SSH theory $[10,11]$ and nomalized to He.

Rates of rise of population in the fundamentals of $\mathrm{CH}_{2} \mathrm{D}_{2}$ are reported in table 1 as best fits to a single exponential rise. All $1 / \tau$ versus pressure plots were linear over the region reported on and all intercepts were zero within experimental error.

\section{Discussion}

An ultimate aim of vibrational energy transfer studies is detailed information about pathways of energy flow. Based on considerations of the magnitude of the energy gap and information gained via studies of methyl halides, the likely pathways for filling the $\left[\nu_{1}, \nu_{6}\right]$ states in $\mathrm{CH}_{2} \mathrm{D}_{2}$ can be narrowed to two:

$$
2 \mathrm{CH}_{2} \mathrm{D}_{2}\left(v_{3}\right) \rightleftharpoons \mathrm{CH}_{2} \mathrm{D}_{2}(0)+\mathrm{CH}_{2} \mathrm{D}_{2}\left(2 v_{3}\right)
$$

and subsequently 


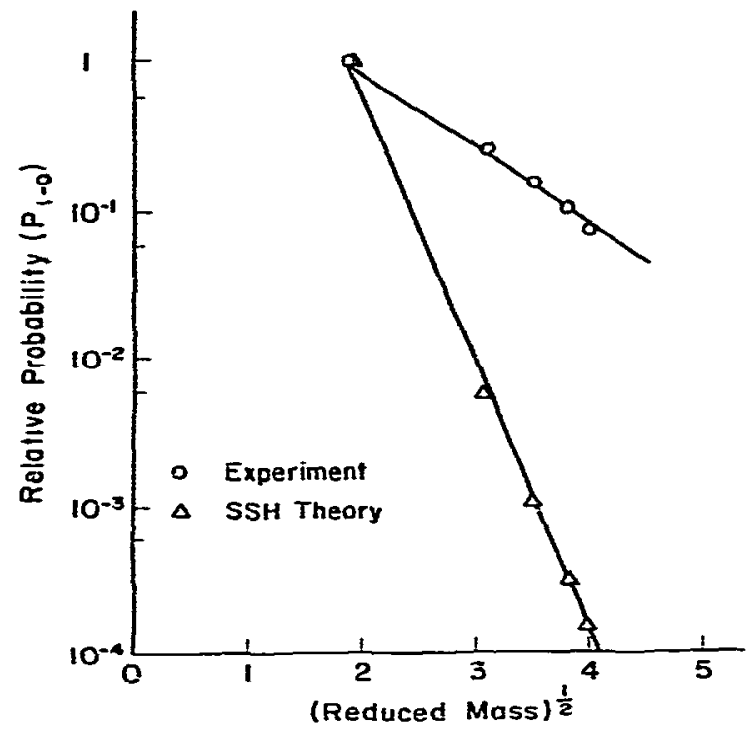

Fis. 2. Semilogarithmic plot of relative deactivation probability per collision, $P_{1-0}$ versus (reduced mass of collision partners) ${ }^{1 / 2}$. For the SSH calculations a breathing sphere parameter of 1 was used. The probabilities were normalized by taking $\boldsymbol{P}_{1-0}=$ 1 for $\mathrm{CH}_{2} \mathrm{D}_{2}-\mathrm{He}$. The experimental rates were converted to $P_{1-0}$ as indicated in the footnote to table 2 , and normalized to He.

$$
\begin{aligned}
& \mathrm{CH}_{2} \mathrm{D}_{2}\left(2 v_{3}\right)+\mathrm{CH}_{2} \mathrm{D}_{2}(0) \\
& \quad \neq \mathrm{CH}_{2} \mathrm{D}_{2}\left(\left[\nu_{1}, v_{6}\right]\right)+\mathrm{CH}_{2} \mathrm{D}_{2}(0),
\end{aligned}
$$

where $\nu_{3}$ could be filled by any of the processes discussed below, or $\left[\nu_{1}, \nu_{6}\right]$ may be filled by an "up the ladder" process involving an overtone of one of the states in the $1000 \mathrm{~cm}^{-1}$ region $\left(2 v_{i}\right)$ colliding with another excited molecule in the same region to yield a triply excited state $\left(2 v_{i}+v_{j}\right)$ near $3000 \mathrm{~cm}^{-1}$, e.g. $3 v_{4}$. A collision of the triply excited state with a ground state molecule would yield a $\left[v_{1}, v_{6}\right]$ molecule. This can be represented as follows:

$2 \mathrm{CH}_{2} \mathrm{D}_{2}\left(v_{i}\right) \rightleftharpoons \mathrm{CH}_{2} \mathrm{D}_{2}\left(2 v_{i}\right)+\mathrm{CH}_{2} \mathrm{D}_{2}(0)$,

followed by

$$
\begin{aligned}
& \mathrm{CH}_{2} \mathrm{D}_{2}\left(2 v_{i}\right)+\mathrm{CH}_{2} \mathrm{D}_{2}\left(v_{i}\right) \\
& \quad \Rightarrow \mathrm{CH}_{2} \mathrm{D}_{2}\left(2 v_{i}+v_{j} j+\mathrm{CH}_{2} \mathrm{D}_{2}(0)\right.
\end{aligned}
$$

and

$$
\begin{aligned}
& \mathrm{CH}_{2} \mathrm{D}_{2}\left(2 v_{i}+v_{j}\right)+\mathrm{CH}_{2} \mathrm{D}_{2}(0) \\
& \quad \approx \mathrm{CH}_{2} \mathrm{D}_{2}\left[v_{1}, v_{6}\right]+\mathrm{CH}_{2} \mathrm{D}_{2}(0) .
\end{aligned}
$$

As a result of preliminary studies involving the rare gas dependence of the rate of rise of the $\left[v_{1}, v_{6}\right]$ states, which will be reported on in detail in a future publication [12], process (1) seems most likely as leading to the equilibration of the $\left[\nu_{1}, \nu_{6}\right]$ modes with the initially pumped mode, though we cannot yet totally rule out process (2).

Filling of the $\nu_{3}$ state can also be limited to a few plausible pathways: $v_{3}$ can fill from below via a process of the type

$$
\begin{aligned}
& \mathrm{CH}_{2} \mathrm{D}_{2}(\mathrm{O})+\mathrm{CH}_{2} \mathrm{D}_{2}\left(\nu_{i}\right) \\
& \rightleftharpoons \mathrm{CH}_{2} \mathrm{D}_{2}\left(v_{3}\right)+\mathrm{CH}_{2} \mathrm{D}_{2}(0) \text {, }
\end{aligned}
$$

or

$$
\begin{aligned}
& \mathrm{CH}_{2} \mathrm{D}_{2}(\mathrm{O})+\mathrm{CH}_{2} \mathrm{D}_{2}\left(\nu_{i}\right) \\
& \rightleftharpoons \mathrm{CH}_{2} \mathrm{D}_{2}\left(\nu_{5}\right)+\mathrm{CH}_{2} \mathrm{D}_{2}(0)
\end{aligned}
$$

and

$$
\begin{aligned}
& \mathrm{CH}_{2} \mathrm{D}_{2}\left(\nu_{5}\right)+\mathrm{CH}_{2} \mathrm{D}_{2}(\mathrm{O}) \\
& \rightleftharpoons \mathrm{CH}_{2} \mathrm{D}_{2}(0)+\mathrm{CH}_{2} \mathrm{D}_{2}\left(\nu_{3}\right),
\end{aligned}
$$

or it can fill from above via a process of the type

$$
\begin{aligned}
& \mathrm{CH}_{2} \mathrm{D}_{2}\left(\nu_{i}\right)+\mathrm{CH}_{2} \mathrm{D}_{2}\left(\nu_{j}\right) \\
& \quad \rightleftharpoons \mathrm{CH}_{2} \mathrm{D}_{2}\left(\nu_{i}+\nu_{j}\right)+\mathrm{CH}_{2} \mathrm{D}_{2}(\mathrm{O})
\end{aligned}
$$

and

$$
\begin{aligned}
& \mathrm{CH}_{2} \mathrm{D}_{2}\left(\nu_{i}+\nu_{j}\right)+\mathrm{CH}_{2} \mathrm{D}_{2}(0) \\
& \quad \rightleftharpoons \mathrm{CH}_{2} \mathrm{D}_{2}\left(\nu_{3}\right)+\mathrm{CH}_{2} \mathrm{D}_{2}(0),
\end{aligned}
$$

where $i, j=4,7,9$. A variety of intermediate steps are possible in (4b). For example, $\nu_{3}$ may be filled through $\nu_{2}$ which is filled via a $\nu_{i}$ combination band.

If $\left[v_{1}, v_{6}\right]$ fills via a process like that in (2) then $\nu_{3}$ could fill from above via the process

$\mathrm{CH}_{2} \mathrm{D}_{2}\left[v_{1}, v_{6}\right]+\mathrm{CH}_{2} \mathrm{D}_{2}(0) \rightleftharpoons 2 \mathrm{CH}_{2} \mathrm{D}_{2}\left(v_{3}\right)$.

Again, due to preliminary results of the dependence of the rise rate of the $v_{3}$ state on rare gas pressure, a pro- 
cess of the type illustrated in eq. (4) seems most likely [12].

The filling of $\nu_{9}$ represents an interesting point regarding symmetry effects on ( $V-V$ transfer) rates. The transition $\nu_{7}\left(B_{1}\right) \rightarrow \nu_{9}\left(B_{2}\right)$ is forbidden according to dipole selection rules in the $C_{2 v}$ group $*$. For small energy gaps, it has been shown that dipole-dipole terms, when present, normally dominate higher multipolar terms in their contribution to the energy transfer process $[13,14]$. One can then consider whether $v_{9}$ would be expected to fill via the dipole non-allowed process

$$
\begin{aligned}
& \mathrm{CH}_{2} \mathrm{D}_{2}\left(v_{7}\right)+\mathrm{CH}_{2} \mathrm{D}_{2}(0) \\
& \quad \rightleftharpoons \mathrm{CH}_{2} \mathrm{D}_{2}\left(v_{9}\right)+\mathrm{CH}_{2} \mathrm{D}_{2}(0),
\end{aligned}
$$

or via an intermediate state

$$
\begin{aligned}
& \mathrm{CH}_{2} \mathrm{D}_{2}\left(\nu_{7}\right)+\mathrm{CH}_{2} \mathrm{D}_{2}(0) \\
& \stackrel{k_{1}}{\underset{k_{2}}{\rightleftharpoons}} \mathrm{CH}_{2} \mathrm{D}_{2}\left(\nu_{4}\right)+\mathrm{CH}_{2} \mathrm{D}_{2}(0)
\end{aligned}
$$

and

$$
\begin{aligned}
& \mathrm{CH}_{2} \mathrm{D}_{2}\left(\nu_{4}\right)+\mathrm{CH}_{2} \mathrm{D}_{2}(0) \\
& \stackrel{k_{3}}{\underset{k_{4}}{\rightleftharpoons}} \mathrm{CH}_{2} \mathrm{D}_{2}\left(\nu_{9}\right)+\mathrm{CH}_{2} \mathrm{D}_{2}(0),
\end{aligned}
$$

where all steps are allowed by dipole seiection rules. For the pressure range observed to date ( 0.4 to 3 torr) and within the limits of our signal to noise level we see only a singic exponential rise for the $\nu_{9}$ population following laser excitation of $\nu_{7}$. While an induction time reflecting a consecutive kinetic process would be expected if $k_{1}$ is comparable to $\vec{k}_{3}$, it has been found by mathematical simulation of the signal, that the induction time would not be observable under our experimental conditions if $k_{1} \gtrsim 3 k_{3}$. This is not an unreasonable expectation considering the small energy gap between $\nu_{7}$ and $\nu_{4}$ and the overlap of their rotation levels. Further studies are underway in an effort to improve signal to noise level via TE laser pumping of $\nu_{7}$ and an effort is being made to pump $\nu_{4}$ and to observe the resulting rise of population of $\nu_{7}$ and $\nu_{9}$ which

\footnotetext{
* The restriction may be relaxed if mixing due to Coriolis forces is sufficient to change the symmetry types of the fundamentals involved.
}

will allow direct determination of the rate constants in eqs. (7a) and (7b) [12]. This will then allow for the evaluation of the role of symmetry in these processes.

\section{1. $V \rightarrow T / R$ rates}

It is again evident, as in many previous studies, that SSH theory is insufficient to describe the variation of the deactivation rate of methane or a substituted methane as a function of rare gas collision partner [2] . For the methyl halides consideration of the combined deactivation effects of translational degrees of freedom as described by SSH theory $[10,11]$ and rotational degrees of freedom as described by $\mathbf{V} \rightarrow \mathbf{R}$ theory result $[15,16]$ in a qualitative reproduction of the features present in the experimental data $[2,17]$. The most striking feature being a leveling off of the deactivation probability as a function of increasing reduced mass of the collision pair. This behavior has also recently been reproduced for a number of the methyl halides by use of a unified $V \rightarrow T / R$ theory [18] .

In $\mathrm{CH}_{2} \mathrm{D}_{2}$ this leveling behavior is not observed. The deactivation rate continues to decrease significantly as a function of reduced mass. The behavior observed in $\mathrm{CH}_{2} \mathrm{D}_{2}$ has also been observed in $\mathrm{CH}_{4}$ [19] and in $\mathrm{CHD}_{3}$ [20] . As indicated in fig. 2 this behavior is not predicted by SSH theory. Nor would it be reproduced by simple $\mathbf{V} \rightarrow \mathbf{R}$ theory which would predict no variation or a very slight variation of rate as a function of reduced mass of the collision partner. It is also doubtful whether a simple synthesis of predictions of $\mathbf{V} \rightarrow \mathbf{T}$ and $\mathbf{V} \rightarrow \mathbf{R}$ theories could produce this behavior assuming reasonable scaling factors for $V \rightarrow T$ and $V \rightarrow R$ contributions [17] - This behavior should present an interesting challenge for a unified $V \rightarrow T / R$ theory.

\section{Conclusions}

Following excitation of $\mathrm{CH}_{2} \mathrm{D}_{2}$ with the $\mathrm{R}(22)$ line of the $9.6 \mu \mathrm{CO}_{2}$ laser transition, fluorescence is observed from 7 of the 8 infrared active fundamentals of $\mathrm{CH}_{2} \mathrm{D}_{2}$ - All states exhibit a $\mathrm{V}-\mathrm{T} / \mathrm{R}$ rate of $1 \mathrm{~ms}^{-1}$ torr $^{-1}$. V-V rates are measured for 6 of the fundamentals with the $3 \mu\left[\nu_{1}, v_{6}\right]$ modes likely filling via a resonant process involving two quanta in the $v_{3}$ mode. The $\nu_{3}$ mode most likely fills from the modes in the $2060 \mathrm{~cm}^{-1}$ region while these modes are most likely 
filled via a resonant process involving two quanta in the modes at $1000 \mathrm{~cm}^{-1}$. The possible role of symmetry effects in filling the $\nu_{9}$ state is discussed. The rates of deactivation of $\mathrm{CH}_{2} \mathrm{D}_{2}$ by rare gases were measured and the dependence of the deactivation of $\mathrm{CH}_{2} \mathrm{D}_{2}$ on rare gas reduced mass cannot be reproduced by simple SSH V-T or V-R theories or a simple superimposition of the two as was found applicable for the methyl halides.

In a future publication we intend to present a much more detailed discussion of the $V-V$ pathways in this system [7].

\section{Acknowledgement}

We would like to thank G. Fujimoto for programming the computer used in this work and G. Fujimoto and R.K. Huddleston for their helpful discussions. We gratefully acknowledge the National Science Foundation for support of this work under Grant CHE 7610333.

\section{References}

[1] E. Weitz and G.W. Flynn, Ann. Rev. Phys. Chem. 25 (1974) 275.

[2] B.L. Earl, L.A. Gamss and A.M. Ronn, Accounts Chem. Res. 11 (1978) 183, and references therein.
[3] J.T. Yardley and C.B. Moore, J. Chem. Phys. 49 (1968) 1111.

[4] P. Hess and C.B. Moore, J. Chem. Phys. 65 (1976) 2339.

[5] V.A. Apkarian and E. Weitz, Presented at the Annual Molecular Spectroscopy Symposium abstract $\frac{1}{\pi} \mathbf{M H} 5$, Columbus, Ohio (1978).

[6] G.T. Fujimoto and E. Weitz, Chem. Phys. 27 (1978) 65.

[7] V.A. Apkarian, M. Moser and E Weitz, work in progress.

[8] J.C. Deroche, J. Phys. 34 (1973) 559.

[9] R.D. Bates Jr., J.T. Knudtson, G.W. Flynn and A.M. Ronn, J. Chem. Phys. 57 (1972) 4174.

[10] J.L. Stretton, Trans. Faraday Soc. 61 (1965) 1053.

[11] P.G. Dickens and A. Ripamonti, Trans. Faraday Soc. 57 (1961) 735 .

[12] V.A. Apkarian and E. Weitz, work in progress.

[13] R.D. Sharma and C.A. Brau, J. Chem. Phys. 50 (1969) 924.

[14] R.D. Sharma, Phys. Rev. 177 (1969) 102.

[15] T.L. Cottrell, R.C. Dobbie, J. McLain and A.W. Read, Trans. Faraday Soc. 60 (1964) 241.

[16] C.B. Moore, J. Chem. Phys. 43 (1965) 2979.

[17] E. Weitz and G.W. Flynn, J. Chem. Phys. 58 (1973) 2679.

[18] A. Miklave and S. Fischer, J. Chem. Phys. 69 (1978) 281.

[19] J.T. Yardley, M.N. Fertig and C.B. Moore, J. Chem. Phys. 52 (1970) 1450.

[20] W.S. Drozdoski, A. Fakhr and R.D. Bates Jr., Chem. Phys. Letters 47 (1977) 309.

[21] J.K. Wilmshurst and H.J. Bernstein, Can. J. Chem. 35 (1957) 226.

[22] R.E. Hiller Jr. and J.W. Straley, J. Mol. Spectry. 5 (1960) 24.

[23] J.O. Hirschfelder, C.F. Curtiss and R.B. Bird, Molecular theory of gases and liquids (Wiley, New York, 1964).

[24] G.A. Stevens and A.E. de Vries, Physica 49 (1968) 346. 